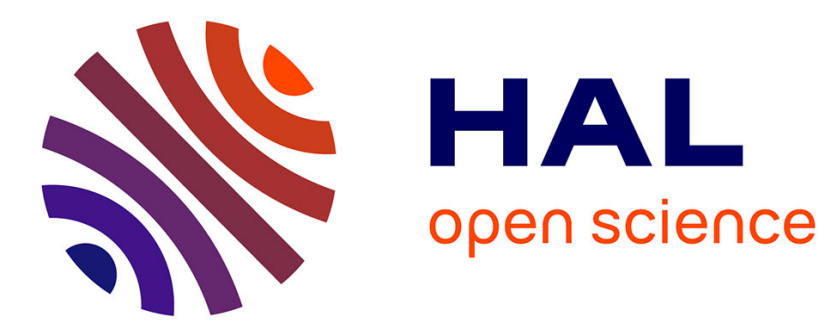

\title{
From Nonlinear Oscillations to Chaos Theory Jean-Marc Ginoux
}

\section{To cite this version:}

Jean-Marc Ginoux. From Nonlinear Oscillations to Chaos Theory. The Foundations of Chaos Revisited: From Poincaré to Recent Advancements, 2016. hal-01856968

\section{HAL Id: hal-01856968 https://hal.science/hal-01856968}

Submitted on 14 Aug 2018

HAL is a multi-disciplinary open access archive for the deposit and dissemination of scientific research documents, whether they are published or not. The documents may come from teaching and research institutions in France or abroad, or from public or private research centers.
L'archive ouverte pluridisciplinaire $\mathbf{H A L}$, est destinée au dépôt et à la diffusion de documents scientifiques de niveau recherche, publiés ou non, émanant des établissements d'enseignement et de recherche français ou étrangers, des laboratoires publics ou privés. 


\title{
From Nonlinear Oscillations to Chaos Theory
}

\author{
Name of First Author and Name of Second Author
}

August 13, 2018

\begin{abstract}
In this work we propose to reconstruct the historical road leading from nonlinear oscillations to chaos theory by analyzing the research performed on the following three devices: the series-dynamo machine, the singing arc and the triode, over a period ranging from the end of the XIX ${ }^{\text {th }}$ century till the end of the Second World War.

Thus, it will be shown that the series-dynamo machine, i.e. an electromechanical device designed in 1880 for experiments, enabled to highlight the existence of sustained oscillations caused by the presence in the circuit of a component analogous to a "negative resistance".

The singing arc, i.e. a spark-gap transmitter used in Wireless Telegraphy to produce oscillations and so to send messages, allowed to prove that, contrary to what has been stated by the historiography till recently, Poincaré made application of his mathematical concept of limit cycle in order to state the existence of sustained oscillations representing a stable regime of sustained waves necessary for radio communication.

During the First World War, the singing arc was progressively replaced by the triode and in 1919, an analogy between series-dynamo machine, singing arc and triode was highlighted. Then, in the following decade, many scientists such as André Blondel, Jean-Baptiste Pomey, Élie and Henri Cartan, Balthasar Van der Pol and Alfred Liénard provided fundamental results concerning these three devices. However, the study of these research has shown that if they made use of Poincaré's methods, they did not make any connection with his works.

In the beginning of the twenties, Van der Pol started to study the oscillations of two coupled triodes and then, the forced oscillations of a triode. This led him to highlight some oscillatory phenomena which have never been observed previously. It will be then recalled that this new kind of behavior considered as "bizarre" at the end of the Second World War by Mary Cartwright and John Littlewood was later identified as "chaotic".
\end{abstract}




\section{Introduction}

The aim of this work is to trace the history of the foundations of Chaos theory through the analysis of the works performed on the following three devices: the series-dynamo machine, the singing arc and the triode, over a period ranging from the end of the XIX ${ }^{t h}$ century till the end of the Second World War.

In 1880 , by sending the current produced by a dynamoelectrical into a magnetoelectrical machine forming thus a series-dynamo machine, the French engineer Jean-Marie Gérard Anatole Lescuyer highlighted a nonlinear phenomenon that will be later considered by Paul Janet as sustained oscillations and by Balthasar Van der Pol as relaxation oscillations ${ }^{1}$. If the cause of this phenomenon was rapidly identified as being the presence in the circuit of a component analogous to a "negative resistance", its mathematical modeling was out of reach at that time.

A quarter of a century later, at the time of the emergence of Wireless Telegraphy, it became of tremendous need to find the condition for which the oscillations produced by a spark-gap transmitter called singing arc were sustained. Actually, this condition representing a stable regime of sustained waves necessary for radio communication was established by Henri Poincaré in 1908 during a series of "forgotten lectures" he gave at the École Supérieure des Postes et Télécommunications (today Telecom ParisTech). Contrary to what was stated by the historiography till recently, Poincaré made thus the first correspondence between the existence of sustained oscillations and the concept of limit cycle that he had introduced in his second memoir "On the curves defined by differential equations". In other words, he proved that the periodic solution of the nonlinear ordinary differential equation characterizing the oscillations of the singing arc corresponds in the phase plane to an attractive closed curve, i.e. a stable limit cycle.

During the First World War, the singing arc was progressively replaced by the triode which was also able to sustain oscillations but even more importantly to amplify the electric signal.

In 1919, the French engineer Paul Janet established an analogy between the series-dynamo machine, the singing arc and the triode and stated thus that their sustained oscillations belong to the same nonlinear phenomenon. Then, in the following decade, many scientists such as André Blondel, Jean-

\footnotetext{
${ }^{1} \mathrm{~A}$ brief history of relaxation oscillations can be found in Ginoux and Letellier [15]. However, let's notice that this article has been entirely republished by M. Letellier in the chapter 2 of his last book while omitting to make correct reference to this work. For a detailed history of relaxation oscillations, see Ginoux [13, 18, 19].
} 
Baptiste Pomey, Élie and Henri Cartan, Balthasar Van der Pol and Alfred Liénard provided fundamental results concerning these three devices. However, it appears that if they made use of Poincaré's methods, they did not make any connection with his works.

In the beginning of the twenties, Van der Pol started to study the oscillations of two coupled triodes and then, the forced oscillations of a triode. This led him to highlight new oscillatory phenomena that he called oscillation hysteresis, automatic synchronization and frequency demultiplication. Nevertheless, in this case, if the oscillations are still sustained, the solution is no more periodic but exhibits a new kind of behavior that will be called "bizarre" at the end of the Second World War by Mary Cartwright and John Littlewood and that will be later identified as "chaotic".

\section{The series-dynamo machine: the expression of nonlinearity}

At the end of the nineteenth century, magneto- or dynamo-electric machines were used in order to turn mechanical work into electrical work and vice versa. With the former type of machine, the magnetic field is induced by a permanent magnet, whereas the latter uses an electromagnet. These machines produced either alternating or direct current indifferently. Thus, in 1880, a French engineer named Jean-Marie-Anatole Gérard-Lescuyer made an experiment by associating a dynamo-electric machine used as a generator with a magneto-electric machine, which in this case can be considered as the motor (Fig. 1).

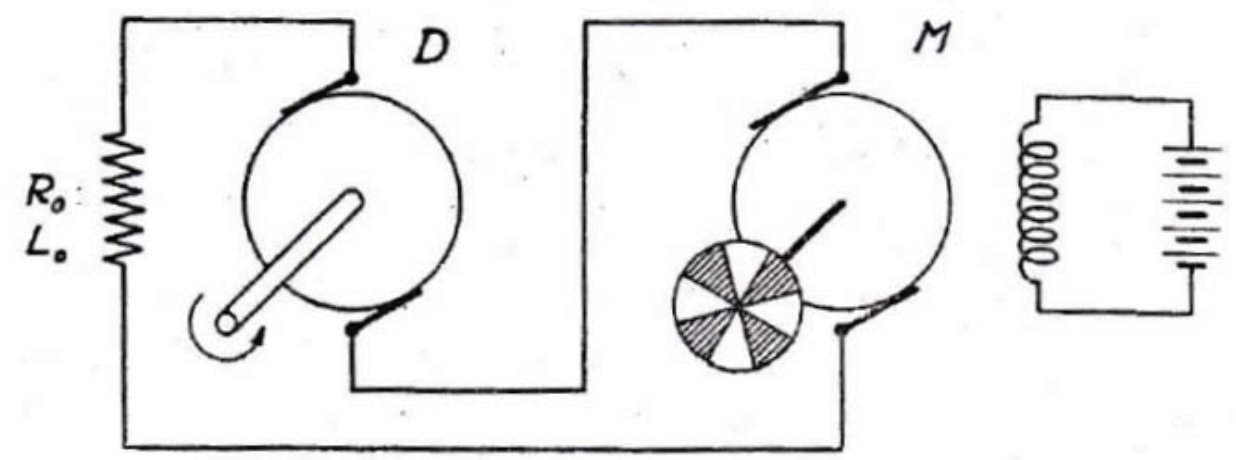

Figure 1: The Gérard-Lescuyer's paradoxical experiment [25]. 
Gérard-Lescuyer $[20,21]$ reports on the found effects in a note published in the Comptes rendus de l'Académie des Sciences de Paris and in the Philosophical Magazine in the following way:

"As soon as the circuit is closed the magnetoelectrical machine begins to move; it tends to take a regulated velocity in accordance with the intensity of the current by which it is excited; but suddenly it slackens its speed, stops, and start again in the opposite direction, to stop again and rotate in the same direction as before. In a word, it receives a regular reciprocating motion which lasts as long as the current that produces it."

While observing the periodical reversal of the magneto-electric machine's circular motion, despite the direct current, he wondered about the causes of this oscillatory phenomenon that he was unfortunately unable to isolate. Gérard-Lescuyer [20, 21] wrote in his conclusion:

"What are we to conclude from this? Nothing, except that we are confronted by a scientific paradox, the explanation of which will come, but which does not cease to be interesting."

It was actually proven by the count Théodose du Moncel [28] a few weeks later, then by Aimé Witz [50, 51], and by Paul Janet [23], that the gap situated between the brushes of the dynamo is the source of an electromotive force (e.m.f.), i.e. a potential difference at its terminals symbolized by a nonlinear function of the intensity that flows through there. However, the mathematical modeling of this e.m.f. was out of reach at that time. Therefore the essence of Gérard-Lescuyer's paradox is the presence of an e.m.f, which has a nonlinear current-voltage characteristic acting as a negative resistance and leading to sustained oscillations.

Half a century later, the famous Dutch physicist Balthasar Van der Pol [46] noted:

"Relaxation oscillations produced by a motor powered by a D.C. series-dynamo. The fact that such a system is able to produce relaxation oscillations was already briefly discussed. In an article written by Mr. Janet (we find a reference to Gérard Lescuyer (CR 91, 226, 1880) where this phenomenon had already been described." 


\section{The singing arc: Poincaré's forgotten lectures}

At the end of the nineteenth century a forerunner to the incandescent light bulb called electric arc was used for lighthouses and street lights. Regardless of its weak glow it had a major drawback: the noise generated by the electrical discharge which inconvenienced the population. In London, physicist William Du Bois Duddell (1872-1917) was commissioned in 1899 by the British authorities to solve this problem. He thought up the association of an oscillating circuit made with an inductor $\mathrm{L}$ and a capacitor $\mathrm{C}$ ( $\mathrm{F}$ on Fig. 2) with the electrical arc to stop the noise (see Fig. 2). Duddell [10, 11] created a device that he named singing arc.

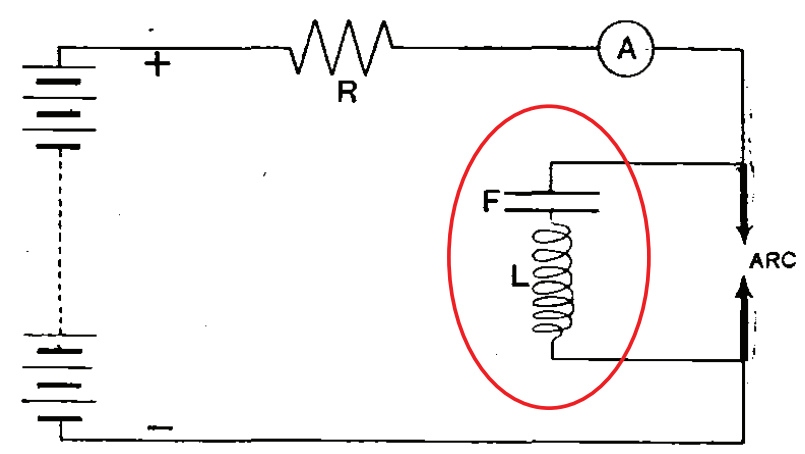

Figure 2: Diagram of the singing arc's circuit, from Duddell [10, 11].

Duddell had actually created an oscillating circuit capable of producing not only sounds (hence its name) but especially electromagnetic waves. This device would therefore be used as an emitter for wireless telegraphy until the triode replaced it. The singing arc or Duddell's arc was indeed a "spark gap" device meaning that it produced sparks which generated the propagation of electromagnetic waves shown by Hertz's experiments as pointed out by Poincaré [30, p. 79]:

"If an electric arc is powered by direct current and if we put a self-inductor and a capacitor in a parallel circuit, the result is comparable to Hertz's oscillator... These oscillations are sustained exactly like those of the pendulum of a clock. We have genuinely an electrical escapement." 
On July $4^{\text {th }} 1902$, Henri Poincaré became Professor of Theoretical Electricity at the École Supérieure des Postes et Télégraphes (Telecom ParisTech) in Paris where he taught until 1910. The director of this school, Édouard Éstaunié (1862-1942), then asked him to give a series of conferences every two years in May-June from 1904 to 1912. He told about Poincaré's first lecture of 1904:

"From the first words it became apparent that we were going to attend the research work of this extraordinary and awesome mathematician... Each obstacle encountered, a short break marked embarrassment, then a blow of shoulder, Poincaré seemed to defy the annoying function."

In 1908, Poincaré chose as the subject: Wireless Telegraphy. The text of his lectures was first published weekly in the journal La Lumière Électrique [31] before being edited as a book the year after [32]. In the fifth and last part of these lectures entitled: Télégraphie dirigée : oscillations entretenues (Directive telegraphy: sustained oscillations) Poincaré stated a necessary condition for the establishment of a stable regime of sustained oscillations in the singing arc. More precisely, he demonstrated the existence, in the phase plane, of a stable limit cycle.

To this aim Poincaré [31] studied Duddell's circuit that he represented by the following diagram (Fig. 3) consisting of an electromotive force (e.m.f.) of direct current $\mathrm{E}$, a resistance $\mathrm{R}$ and a self-induction, and in parallel, a singing arc and another self-induction $\mathrm{L}$ and a capacitor.

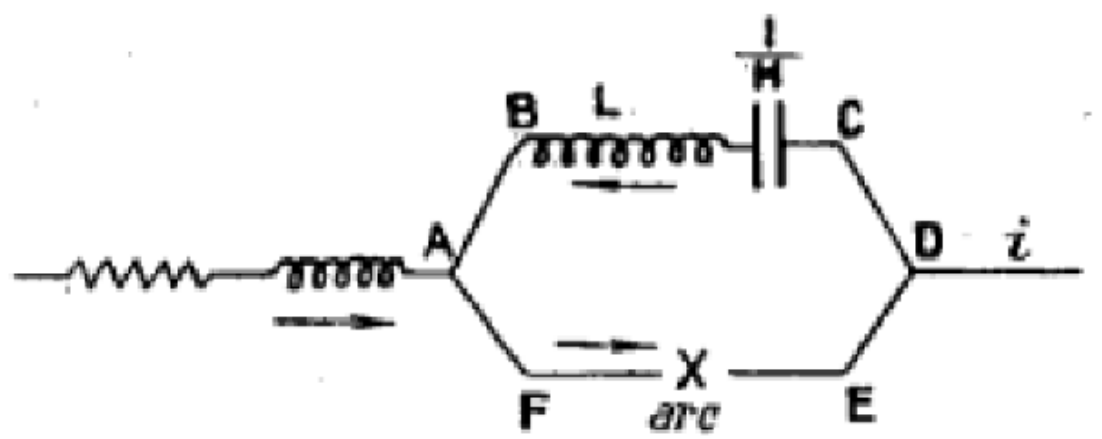

Figure 3: Circuit diagram of the singing arc, from Poincaré [31, p. 390].

Then, he called $x$ the capacitor charge, $x^{\prime}$ the current intensity in the branch including the capacitor, $\rho x^{\prime}$ the term corresponding to the internal 
resistance of the self and various damping and $\theta\left(x^{\prime}\right)$ the term representing the e.m.f. of the arc the mathematical modeling of which was also out of reach for Poincaré at that time. Nevertheless, Poincaré was able to establish the singing arc equation, i.e. the second order nonlinear differential equation (1) for the sustained oscillations in the singing arc:

$$
L x^{\prime \prime}+\rho x^{\prime}+\theta\left(x^{\prime}\right)+H x=0
$$

Then, by using the qualitative theory of differential equations that he developed in his famous memoirs [33, 37], he stated that:

"One can construct curves satisfying this differential equation, provided that function $\theta$ is known. Sustained oscillations correspond to closed curves, if there exist any. But every closed curve is not appropriate, it must fulfill certain conditions of stability that we will investigate."

Thus, he plotted a representation of the solution of equation (1):

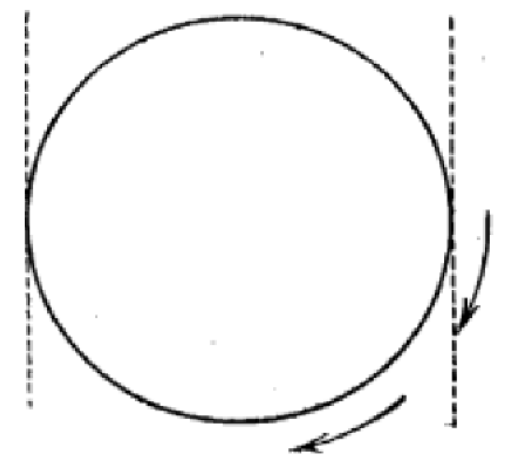

Figure 4: Closed curve solution of the sing arc equation, from Poincaré [31, p. 390].

Let's notice that this closed curve is only a metaphor of the solution since Poincaré does not use any graphical integration method such as isoclines. This representation led him to state the following stability condition:

"Stability condition. - Let's consider another non-closed curve satisfying the differential equation, it will be a kind of spiral curve approaching indefinitely near the closed curve. If the closed curve represents a stable regime, by following the spiral in the 
direction of the arrow one should be brought back to the closed curve, and provided that this condition is fulfilled the closed curve will represent a stable regime of sustained waves and will give rise to a solution of this problem."

Then, it clearly appears that the closed curve which represents a stable regime of sustained oscillations is nothing else but a limit cycle as Poincaré [34, p. 261] has introduced it in his own famous memoir "On the curves defined by differential equations" and as Poincaré [35, p. 25] has later defined it in the notice on his own scientific works [35]. But this, first giant step is not sufficient to prove the stability of the oscillating regime. Poincaré had to demonstrate now that the periodic solution of equation (1) (the closed curve) corresponds to a stable limit cycle. So, in the next part of his lectures, Poincaré gave what he calls a "condition de possibilité du problème". In fact, he established a stability condition of the periodic solution of equation (1), i.e. a stability condition of the limit cycle under the form of the following inequality.

$$
\int \theta\left(x^{\prime}\right) x^{\prime} d t<0
$$

It has been proved by Ginoux $[12,13,16,18,19]$ that this stability condition (2) flows from a fundamental result introduced by Poincaré in the chapter titled "Exposants caractristiques" ("Characteristics exponents") of his "New Methods of Celestial Mechanics" [38, Vol. I, p. 180].

Until recently the historiography considered that Poincaré did not make any connection between sustained oscillations and the concept of limit cycle he had introduced and credited the Russian mathematician Aleksandr' Andronov [1, 2] for having been the "first" to establish this correspondence between periodic solution and limit cycle.

Concerning the singing arc, Van der Pol [49] also noted in the beginning of the thirties:

"In the electric field we have some very nice examples of relaxation oscillations, some are very old, such as spark discharge of a plate machine, the oscillation of the electric arc studied by Mr. Blondel in a famous memoir (1) or the experience of Mr. JANET, and other more recent..."

(1) BLONDEL, Eclair. Elec., 44, 41, 81, 1905. See also J. de Phys., 8, 153, 1919. 


\section{The triode:}

\section{from periodic solution to limit cycle}

In 1907, the American electrical engineer Lee de Forest (1873-1961) invented the audion. It was actually the first triode developed as a radio receiver detector. Curiously, it found little use until its amplifying ability was recognized around 1912 by several researchers. Then, it progressively replaced the singing arc in the wireless telegraphy devices and underwent a considerable development during the First World War. Thus, in October 1914, a few months after the beginning of the conflict, the French General Gustave Ferrié (1868-1932), director of the Radiotélégraphie Militaire department, gathered a team of specialists whose mission was to develop a French audion, which should be sturdy, have regular characteristics, and be easy to produce industrially. Ferrié asked to the French physicist Henri Abraham (1868-1943) to recreate Lee de Forests' audions. However, their fragile structure and lack of stability made them unsuitable for military use. After several unsuccessful attempts, Abraham created a fourth structure in December 1914, which was put in operation from February to October 1915 (Fig. 5).

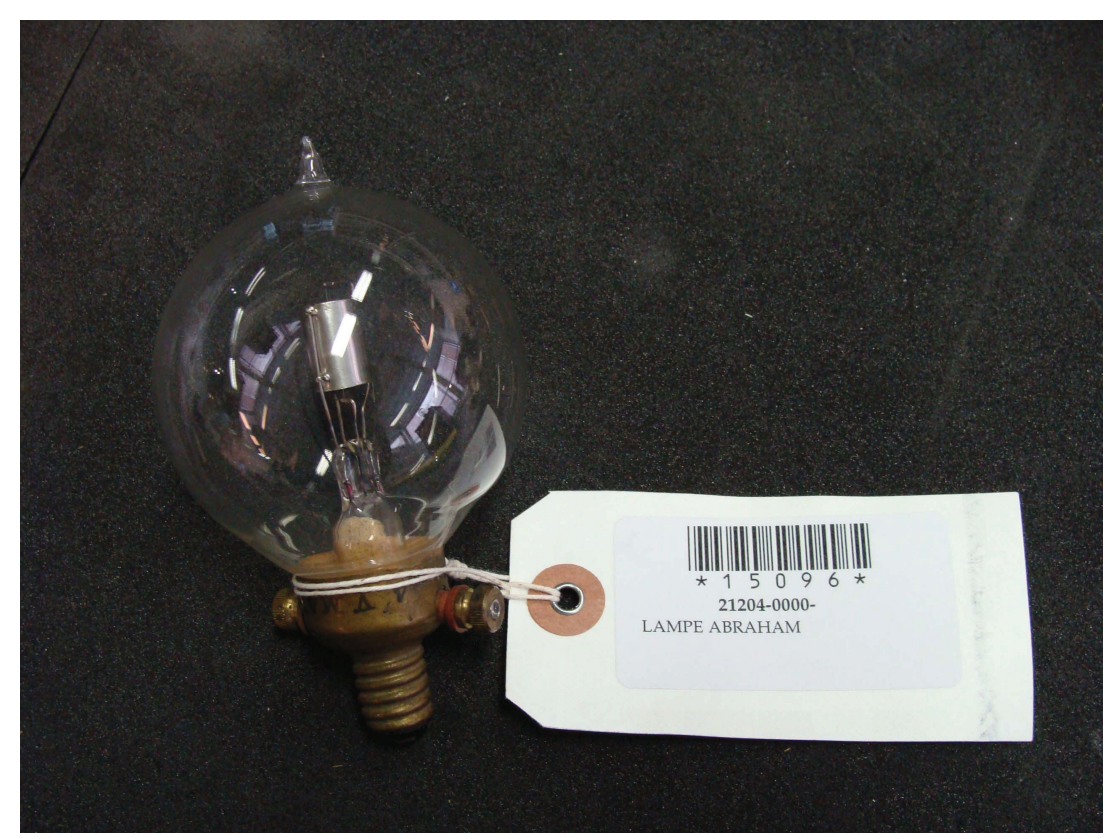

Figure 5: Picture of the original lamp T.M. made by Abraham (1915). 
The original of this valve called "Abraham lamp" is still in the Arts et Métiers museum to this day (Fig. 5). It has a cylindrical structure, which appears to have been designed by Abraham. In November 1917, Abraham consequently invented with his colleague Eugene Bloch (1878-1944) a device able to measure wireless telegraphy emitter frequencies: the so-called multivibrator (see Ginoux [13, 16, 18, 19]).

Wireless telegraphy development, spurred by war effort, went from craft to full industrialization. The triode valves were then marketed on a larger scale. More reliable and stable than the singing arc, the consistency of the various components used in the triode allowed for exact reproduction of experiments, which facilitated research on sustained oscillations.

\subsection{Janet's analogy}

In April 1919, the French scientist Paul Janet (1863-1937) published an article entitled "Sur une analogie électrotechnique des oscillations entretenues" [24] which was of considerable importance on several levels. Firstly, it underscored the technology transfer taking place, consisting in replacing an electromechanical component (singing arc) with what would later be called an electronic tube. This represented a true revolution since the singing arc, because of its structure it made experiments complex and tricky, making it almost impossible to recreate. Secondly, it revealed "technological analogy" between sustained oscillations produced by a series dynamo machine like the one used by Gérard-Lescuyer $[20,21]$ and the oscillations of the singing arc or a three-electrode valve (triode). Janet [24, p. 764] wrote:

"It seemed to me interesting to mention the unexpected analogies of this experiment with the sustained oscillations so widely used to-day in wireless telegraphy, for example, those produced in Duddell's arc or in the lamp with three-electrodes lamps used as oscillators... Producing and sustaining oscillations in these systems mostly depends on the presence, in the oscillating circuit, of something comparable to a negative resistance. The dynamo-series acts as a negative resistance, and the engine with separated excitation acts as a capacity."

Thus, Janet considered that in order to have analogies in the effects, i.e. in order to see the same type of oscillations in the series-dynamo machine, the triode and the singing arc, there must be an analogy in the causes. Therefore, since the series-dynamo machine acts as a negative resistance, 
responsible for the oscillations, there is indeed an analogy. Consequently, only one equation must correspond to these devices. In this article, Janet provided the nonlinear differential equation characterizing the oscillations noted during Gérard-Lescuyer's experiment:

$$
L \frac{d^{2} i}{d t^{2}}+\left[R-f^{\prime}(i)\right] \frac{d i}{d t}+\frac{k^{2}}{K} i=0
$$

where $R$ corresponds to the resistance of the series dynamo machine, $L$ is the self-induction of the circuit and $K / k^{2}$ is analogous to a capacitor and $f(i)$ is the electromotive force of the series-dynamo machine. However, as recalled by Janet [24, p. 765], its mathematical modeling was also out of reach at that time.

"But the phenomenon is limited by the characteristic's curvature, and regular, non-sinusoidal equations actually occur. They are governed by the equation (3), which could only be integrated if we knew the explicit for of the function $f(i)$."

By replacing in Eq. (3) $i$ with $x, R$ with $\rho, f^{\prime}(i)$ with $\theta(x)$, and $k^{2} / K$ with $H$, one find again Poincaré's singing arc equation (2). Thus, both ordinary differential equations are analogous but are not of the same order. Nevertheless, it appeared that Janet did make no connection with Poincaré's works.

\subsection{Blondel's triode equation}

According to the historiography, it is common knowledge the Dutch physicist Balathasar Van der Pol is credited for having stated the differential equation of the triode in his famous publication entitled "On relaxation oscillations" published in 1926 [45]. However, it was proved by Ginoux [13, 16, 17] on the one hand that the triode equation was actually stated by Van der Pol in 1920 in a publication entitled: "A theory of the amplitude of free and forced triode vibrations," [40] and on the other that the French engineer André Blondel sated the triode equation one year before him.

As previously pointed out, the main problem of these three devices was the mathematical modeling of their oscillation characteristics, i.e., the e.m.f. of the series-dynamo machine, of the singing arc and of the triode.

Thus, in a note published in the Comptes Rendus of the Académie des Sciences on the $17^{\text {th }}$ of November 1919, Blondel proposed to model the oscillation characteristic of the triode as follows [3]: 


$$
i=b_{1}(u+k \nu)-b_{3}(u+k \nu)^{3}-b_{5}(u+k \nu)^{5} \ldots
$$

Then, substituting $i$ by its expression in the triode equation, neglecting the internal resistors and integrating once with respect to time, he obtained

$$
C \frac{\mathrm{d}^{2} u}{\mathrm{~d} t^{2}}-\left(b_{1} h-3 b_{3} h^{3} u^{2}-\ldots\right) \frac{\mathrm{d} u}{\mathrm{~d} t}+\frac{u}{L}=0
$$

Let's notice that this equation is perfectly equivalent to those obtained by Poincaré and Janet. Nevertheless, if Blondel solved the problem of the mathematical modeling of the oscillation characteristic of the triode he did make no connection with Poincaré's works despite of the fact that he knew him personally.

\subsection{Pomey's contribution}

Less than on year later, the French engineer Jean-Baptiste Pomey (18611943) proposed a mathematical modeling of the e.m.f. of the singing arc in his entitled: "Introduction à la théorie des courants téléphoniques et de la radiotélégraphie " and published on June $28^{\text {th }} 1920$ (this detail would be of great importance in the following). Pomey [39, p. 375] wrote:

"For the oscillations to be sustained it is not enough to have a periodic motion, it is necessary to have a stable motion."

Then, he proposed the following "law" for the e.m.f. of the singing arc:

$$
E=E_{0}+a i-b i^{3}
$$

and posing $i=x^{\prime}$ (like Poincaré) he provided the nonlinear differential equation of the singing arc:

$$
L x^{\prime \prime}+R x^{\prime}+\frac{1}{C} x=E_{0}+a x^{\prime}-b x^{\prime 3}
$$

By posing $H=1 / C, \rho=R$ and $\theta\left(x^{\prime}\right)=-E_{0}-a x^{\prime}+b x^{\prime 3}$ it is obvious that Eq. (1) and Eq. (7) are completely identical ${ }^{2}$. Moreover, it is striking to observe that Pomey has used exactly the same variable $x^{\prime}$ as Poincaré to represent the current intensity. Here again, there is no reference to Poincaré. This is very surprising since Pomey was present during the last lecture of Poincaré at the École Supérieure des Postes et Télégraphes in 1912 whose

\footnotetext{
${ }^{2}$ For more details see Ginoux [16 $\left., 17,18,19\right]$.
} 
he had written the introduction. So, one can imagine that he could have attended the lecture of 1908 .

At the same time, Van der Pol [40] proposed the following mathematical modeling of the oscillation characteristic of the triode in an article published on July 17, 1920:

$$
i=\psi(k v)=\alpha v+\beta v^{2}+\gamma v^{3}
$$

Van der Pol $[40$, p. 704$]$ precised that, by symmetry consideration, one can choose $\beta=0$ and provided the triode equation:

$$
C \frac{d^{2} v}{d t^{2}}-\left(\alpha-3 \gamma v^{2}\right) \frac{d v}{d t}+\frac{1}{L} v=0
$$

Taking into account that $\beta$ can be chosen as equal to zero, one finds no difference between the Eq. (6) and the Eq. (8). Nevertheless, nothing proves that Van der Pol had read Pomey's book.

Five years later, on September $28^{\text {th }}$ 1925, Pomey wrote a letter to the mathematician Élie Cartan (1869-1951) in which he asked him to provide a condition for which the oscillations of an electrotechnics device analogous to the singing arc and to the triode whose equation is exactly that of Janet (3) are sustained. Within ten days, Élie Cartan and his son Henri sent an article entitled: "Note sur la génération des oscillations entretenues" [4] in which they proved the existence of a periodic solution for Janet's equation (3). In fact, their proof was based on a diagram which corresponds exactly to a "first return map" diagram introduced by Poincaré in his memoir "Sur les Courbes définies par une équation différentielle" [34, p. 251].

\subsection{Van der Pol's relaxation oscillations}

Van der Pol's most famous publication is probably that entitled "On relaxation oscillations" [45]. However, what is least well-known is that he published four different versions of this paper in 1926 in the following order:

1. Over Relaxatietrillingen [42] (in Dutch);

2. Over Relaxatie-trillingen [43] (in Dutch);

3. Über Relaxationsschwingungen [44] (in German);

4. On relaxation-oscillations [45] (in English). 
In these four articles, Van der Pol presents the following generic dimensionless nonlinear differential equation for relaxation oscillations which is neither attached to the triode, nor to any other device (series-dynamo machine or singing arc):

$$
\ddot{v}-\varepsilon\left(1-v^{2}\right) \dot{v}+v=0 .
$$

Early on, Van der Pol [40, p. 179] realized that the equation (10) was not analytically integrable:

"It has been found to be impossible to obtain an approximate analytical solution for (10) with the supplementing condition $(\varepsilon \ll 1)$, but a graphical solution may be found in the following way."

So, he used the isoclynes method to graphically integrate the nonlinear differential equation (10) for the relaxation oscillations.

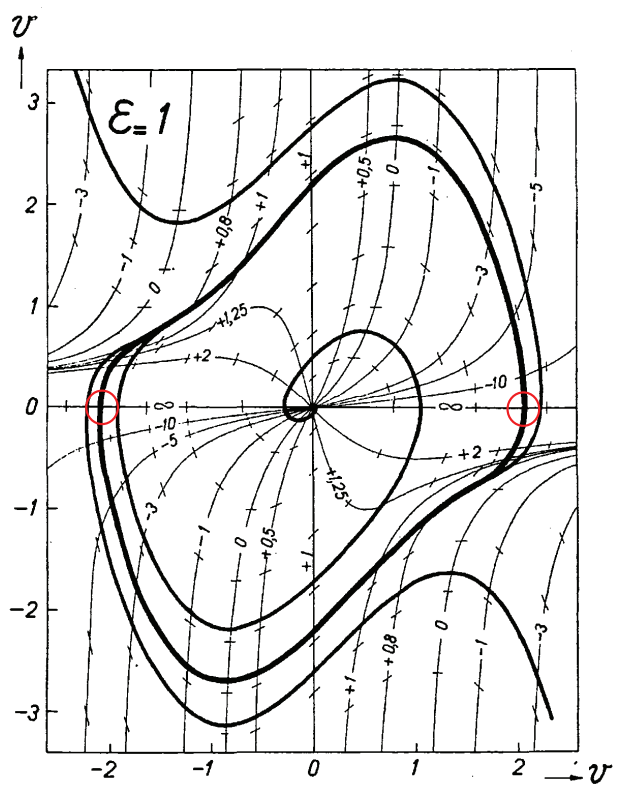

Figure 6: Graphical integration of equation (10)

Obviously, the solution plotted on this figure is nothing else but a limit cycle of Poincaré. Nevertheless, contrary to a widespread view, Van der Pol didn't recognize this signature of a periodic solution and did make no 
connection with Poincaré's works till 1930! On the occasion of a series of lectures that he made at the École supérieure d'Électricité on March $10^{\text {th }}$ and $11^{\text {th }}$ 1930, Van der Pol wrote [49]:

"Note on each of these three figures a closed integral curve, which is an example of what Poincaré called a limit cycle, because the neighboring integral curves are approaching asymptotically."

Moreover, let's notice that he didn't make any reference to Poincaré's works but to Andronov's article [2].

\subsection{Liénard's riddle}

On May 1928, the French engineer Alfred Liénard (1869-1958) published an article entitled "Étude des oscillations entretenues" in which he studied the solution of the following nonlinear differential equation:

$$
\frac{d^{2} x}{d t^{2}}+\omega f(x) \frac{d x}{d t}+\omega^{2} x=0
$$

Such an equation is a generalization of the well-known Van der Pol's equation and of course of Janet's equation (4). Under certain assumptions on the function $F(x)=\int_{0}^{x} f(x) d x$ less restrictive than those chosen by Cartan [4] and Van der Pol [45], Liénard [26] proved the existence and uniqueness of a periodic solution of Eq. (11). Then, Liénard [26, p. 906] plotted this solution (Fig. 7) and wrote:

"All integral curves, interior or exterior, traveled in the direction of increasing time, tend asymptotically to the curve D, we say that the corresponding periodic motion is a stable motion."

Then, Liénard [26, p. 906] explained that the condition for which the "periodic motion" is stable is given by the following inequality:

$$
\int_{\Gamma} F(x) d y>0
$$

By considering that the trajectory curve describes the closed curve clockwise in the case of Poincaré and counter clockwise in the case of Liénard, it is easy to show that both conditions (2) and (12) are completely identical ${ }^{3}$ and represents an analogue of what is now called "orbital stability". Again, one

${ }^{3}$ For more details see Ginoux [13 $\left., 16,17,18,19\right]$. 


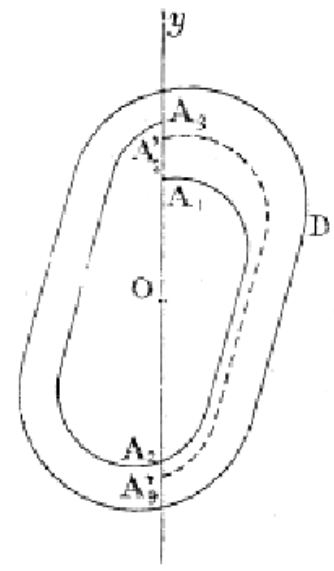

Figure 7: Closed curve solution of Eq. (10), Liénard [26].

can find no reference to Poincaré's works in Liénard's paper. Moreover, it is very surprising to observe that he didn't used the terminology "limit cycle" to describe its periodic solution. All these facts constitutes the Liénard's riddle.

\subsection{Andronov's note at the Comptes Rendus}

On Monday 14 October 1929, the French mathematician Jacques Hadamard (1865-1963) presented to the Académie des Sciences de Paris a note which was sent to him by Aleksandr Andronov and entitled "Poincaré's limit cycles and the theory of self-sustained oscillation". In this work, Andronov [2] proposed to transform the second order nonlinear differential equation modeling the sustained oscillations by the series-dynamo machine, the singing arc or the triode into the following set of two first order differential equations:

$$
\frac{d x}{d t}=P(x, y) \quad ; \quad \frac{d y}{d t}=Q(x, y)
$$

Then, he explained that the periodic solution of this system (13) is expressed in terms of Poincaré's limit cycles:

"This results in self-oscillations which emerge in the systems characterized by the equation of type (13) corresponding mathematically to Poincaré's stable limit cycles." 
It is important to notice that due to the imposed format of the Comptes Rendus (limited to four pages), Andronov did not provide any demonstration. He just claimed that the periodic solution of a non-linear second order differential equation defined by (13) "corresponds" to Poincaré's stable limit cycles. Then, Andronov provided a stability condition for the stability of the limit cycle:

$$
\int_{0}^{2 \pi}\left[f_{x}(R \cos \xi,-R \sin \xi ; 0) \cos \xi+g_{y}(R \cos \xi,-R \sin \xi ; 0) \sin \xi\right] d \xi<0
$$

In fact, this condition is based on the use of characteristic exponents introduced by Poincaré in his so-called New Methods on Celestial Mechanics [38, Vol. I, p. 161] and after by Lyapounov in his famous textbook General Problem of Stability of the Motion [27]. That's the reason why Andronov will call later the stability condition (14): stability in the sense of Lyapounov or Lyapounov stability. It has been stated by Ginoux [12, 13, 16, 18, 19] that both stability condition of Poincaré (2) and of Andronov (14) are totally identical. Thus by comparing Andronov's previous sentence with that of Poincaré (see above), it clearly appears that Andronov has stated the same correspondence as Poincaré twenty years after him. Nevertheless, it seems that Andronov may not have read Poincaré's article since at that time even if the first volume of his complete works had been already published it didn't contained Poincaré's lectures on Wireless Telegraphy.

\subsection{The first "lost" International Conference on Nonlinear Oscillations}

From 28 to 30 January 1933 the first International Conference of Nonlinear Oscillations was held at the Institut Henri Poincaré (Paris) organized at the initiative of the Dutch physicist Balthasar Van der Pol and of the Russian mathematician Nikolaï Dmitrievich Papaleksi. This event, of which virtually no trace remains, was reported in an article written in Russian by Papaleksi at his return in USSR. This document, recently rediscovered by Ginoux [14], has revealed, on the one hand, the list of participants who included French mathematicians: Alfred Liénard, Élie and Henri Cartan, Henri Abraham, Eugène Bloch, Léon Brillouin, Yves Rocard .... and, on the other hand the content of presentations and discussions. The analysis of the minutes of this conference highlights the role and involvement of the French scientific 
community in the development of the theory of nonlinear oscillations ${ }^{4}$.

According to Papaleksi [29, p. 211], during his talk, Liénard recalled the main results of his study on sustained oscillations:

"Starting from its graphical method for constructing integral curves of differential equations, he deduced the conditions that must satisfy the nonlinear characteristic of the system in order to have periodic oscillations, that is to say for that the integral curve to be a closed curve, i.e. a limit cycle."

This statement on Liénard must be considered with great caution. Indeed, one must keep in mind that Papaleksi had an excellent understanding of the work of Andronov [2] and that his report was also intended for members of the Academy of the USSR to which he must justified his presence in France at this conference in order to show the important diffusion of the Soviet work in Europe. Despite the presence of MM. Cartan, Lienard, Le Corbeiller and Rocard it does not appear that this conference has generated, for these scientists, a renewed interest in the problem of sustained oscillations and limit cycles.

\section{The triode: from limit cycle to "bizarre" solutions}

At the end of the First World War, the development of wireless telegraphy led the engineers and scientists to turn to the study of self-sustained oscillations in a three-electrode lamp subjected to a periodic "forcing" or a "coupling". According to Mrs. Mary Lucy Cartwright [9]:

"The non-linearity [in the Van der Pol equation] may be said to control the amplitude in the sense that it allows it to increase when it is small but prevents it becoming too large. The general solution cannot be obtained by the combination of two linearly independent solutions and similar difficulties arise when we add a forcing term to this equation. This was brought out very clearly by the work of van der Pol and Appleton, partly in collaboration, and partly independently, in a series of papers on radio oscillations published between 1920 and 1927. To me the work of the radio engineers is much more interesting and suggestive

${ }^{4}$ For more details see Ginoux [13 $\left., 16,14,18,19\right]$. 
than that of the mechanical engineers. The radio engineers want their systems to oscillate, and to oscillate in a very orderly way, and therefore they want to know not only whether the system has a periodic solution, but whether it is stable, what its period and amplitude and harmonic content are, and how these vary with the parameters of the equation, and they sometimes want the period to be determined with a very small error. In the early days they wanted to explain why the amplitude was limited in a certain way and why in some cases the period lengthened as the harmonic content increased and not in others. The desire to know why and the insistence on how the various quantities such as amplitude and frequency vary with the parameters of the equation over fairly wide ranges meant that numerical and graphical solutions either failed to provide the answer or were far too cumbersome. Further, unless one knows something about the general behavior of the solutions, the numerical work, which is only approximate, may be misleading."

Thus, in the beginning of the 1920s, Van der Pol [40] studied the oscillations of a forced triode, i.e. a triode powered by a voltage generator with an f.e.m. of type $v(t)=E_{s} i n\left(\omega_{1} t\right)$ the equation of which reads then:

$$
\ddot{v}-\alpha\left(1-v^{2}\right) \dot{v}+\omega_{0}^{2} v=\omega_{1}^{2} E_{s} i n\left(n \omega_{1} t\right) \quad \text { with } \quad \varepsilon=\frac{\alpha}{\omega_{0}} \ll 1
$$

Four years later, while using the method of "slowly-varying amplitude" that he had developed, Van der Pol [41] was thus able on the one hand to obtain more directly the various approximations of the amplitude of this forced system, and on the other hand, to construct a solution to the equation more easily than by using the classical Poincar-Lindstedt or Fourier methods ${ }^{5}$. In this paper, Van der Pol [47] highlights the fact that when the difference in frequency of the two signals is inferior to this value an automatic synchronization phenomenon occurs and the two circuits oscillate with the same frequency. This led him to evidence the phenomenon of frequency entrainment, which he defined thus:

"Hence the free frequency undergoes a correction in the direction of the forced frequency, giving the impression as if the free frequency were being attracted by the forced frequency."

\footnotetext{
${ }^{5}$ The English version of this article was published in 1927. See Van der Pol [47].
} 
In 1927, Van der Pol and his colleague Jan Van der Mark [48] published an article titled "Frequency Demultiplication," in which they again studied the forced oscillations of a triode, but in the field of relaxation oscillations. Then, they explained that the automatic synchronization phenomenon, observed in the case of the forced oscillations of a triode, can also occur for a range of the parameter corresponding to the relaxation oscillations, i.e. for $\varepsilon \gg 1$, but in a much wider frequency field. They also reported that the resonance phenomenon is almost non-existent in forced relaxation oscillations, and that consequently, the sinusoidal e.m.f. inducing the forcing influences the period (or frequency) of the oscillations more than it does their amplitude, and added:

"It is found that the system is only capable of oscillating with discrete frequencies, these being determined by whole sub-multiples of the applied frequency."

In their article, Van der Pol and Van der Mark [48] proposed, in order to evidence the frequency demultiplication phenomenon, the following construction (see Fig. 8) on which we can see a "jump" of the period for each increase in the value of the capacitor's capacitance.

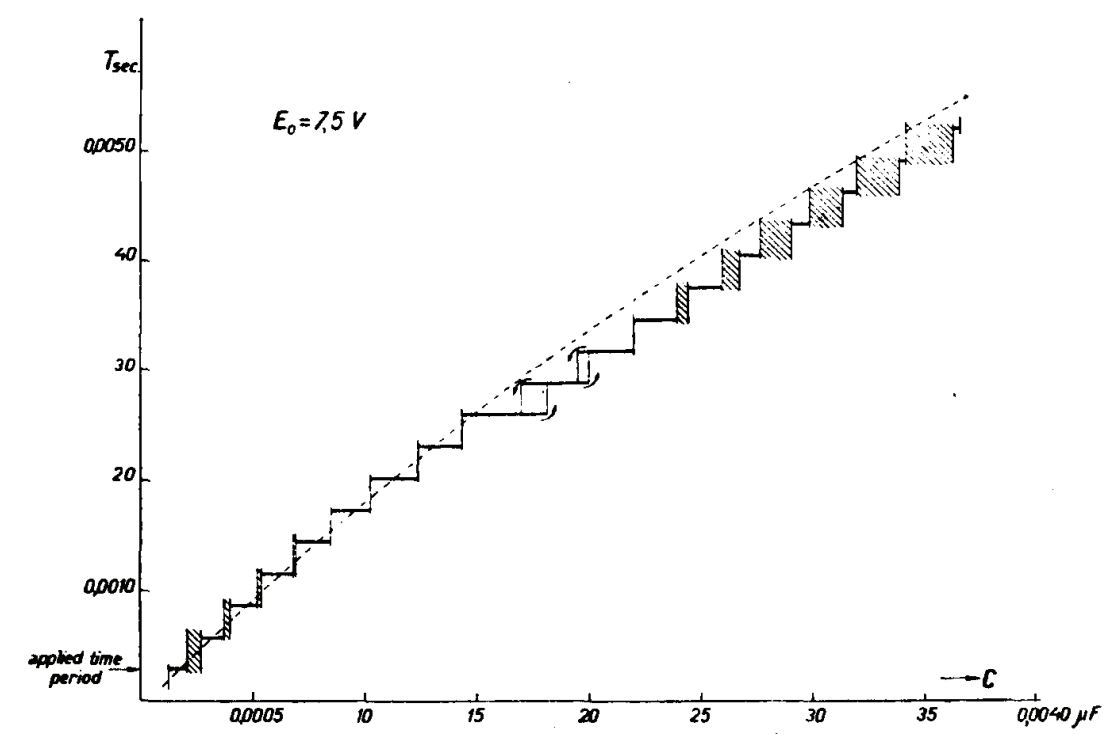

Figure 8: Representation of the phenomenon of frequency demultiplication, from Van der Pol et Van der Mark [48, p. 364]. 
In order to evidence this frequency demultiplication phenomenon, Van der Pol and Van der Mark used a phone. They then described the phenomenon what they heard in the receiver:

"Often an irregular noise is heard in the telephone receivers before the frequency jumps to the next lower value. However, this is a subsidiary phenomenon, the main effect being the regular frequency multiplication."

This irregular noise they heard was actually the sound manifestation of the transition which was taking place. Indeed, as the frequency varied, the solution to the differential equation (15), which had been until now represented by a limit cycle, i.e. by a periodic attractor, would draw a "strange attractor" transcribing the chaotic behavior of the solution. Van der Pol seemed to have reached the limits of deterministic physics with how far he went in the exploration of nonlinear and non-autonomous systems. He "flirted", as Mary Lucy Cartwright and John Edensor Littlewood [5, 6, 7, 8] did twenty years later with the first signs of chaos, when they called "bizarre" the behavior of the solution to the differential equation (15) for specific values of the parameters. Indeed, according to Guckenheimer et al. [22]:

"Van der Pol's work on nonlinear oscillations and circuit theory provided motivation for the seminal work of Cartwright and Littlewood. In 1938, just prior to World War II, the British Radio Research Board issued a request for mathematicians to consider the differential equations that arise in radio engineering. Responding to this request, Cartwright and Littlewood began studying the forced van der Pol equation and showed that it does indeed have bistable parameter regimes. In addition, they showed that there does not exist a smooth boundary between the basins of attraction of the stable periodic orbits. They discovered what is now called chaotic dynamics by detailed investigation of this system."

\section{Conclusion}

Thus, the analysis of the research performed on the following three devices: the series-dynamo machine, the singing arc and the triode, over a period ranging from the end of the XIX ${ }^{\text {th }}$ century till the end of the Second World War, has enabled to reconstruct the historical road leading from nonlinear 
oscillations to chaos theory. The series-dynamo machine has highlighted a new kind of oscillations generated by the presence of a nonlinear component in the circuit, i.e. a negative resistance. Poincaré's work on the singing arc has provided an analytical condition for the sustaining of these oscillations, i.e. for the existence of a stable limit cycle. Moreover, this has proved that Poincaré has established twenty years before Andronov the correspondence between periodic solution and stable limit cycle. In his research on the triode, Blondel has solved the question of the mathematical modeling of its oscillation characteristic, i.e. of its negative resistance and stated thus, one year before Van der Pol, the triode's equation. Then, Janet highlighted an analogy between the oscillations sustained by the series-dynamo machine, the singing arc and the triode and Van der Pol deduced that they were belonging to the same oscillatory phenomenon that he called relaxation oscillations. Though he plotted the solution of the equation that now bears his name, he didn't recognize that it was obviously a Poincaré's limit cycle. Thereafter, Cartan and then Liénard proved the existence and uniqueness of this periodic solution but did not make either a connection with Poincaré's works. Immediately after Andronov established this connection, Van der Pol and Papaleksi organized the first International Conference on Nonlinear Oscillations in Paris. Nevertheless, this meeting did not lead to any development or research in this field. At the same time, Van der Pol and Van der Mark highlighted that the forced triode was the source of a strange phenomenon that they called frequency demultiplication. At the end of the Second World War, Cartwright and Littlewood investigated this system and considered its oscillations as "bizarre". Many years later, it appeared that they had actually observed the first chaotic behavior.

\section{References}

[1] A.A. Andronov, Предельные циклы Пуанкаре и теория колебаний, in IVs'ezd ruskikh fizikov (5-16.08, p. 23-24). (Poincaré's limit cycles and the theory oscillations), this report has been read guring the $\mathrm{IV}^{\text {th }}$ congress of Russian physicists in Moscow between 5 to 16 August 1928, p. 23-24.

[2] A.A. Andronov, Les cycles limites de Poincaré et la théorie des oscillations auto-entretenues, Comptes Rendus de l'Académie des Sciences, 189, 559-561 (14 October 1929). 
[3] A. Blondel, Amplitude du courant oscillant produit par les audions générateurs, Comptes-Rendus de l'Académie des Sciences, 169, 943948 (17 November 1919).

[4] E. \& H. Cartan, Note sur la génération des oscillations entretenues, Annales des P.T.T., 14, 1196-1207 (1925).

[5] M.L. Cartwright \& J. Littlewood, On non-linear differential equations of the second order, I: The Equation $\ddot{y}-k\left(1-y^{2}\right) \dot{y}+y=$ $b \lambda k \cos (\lambda t+a), k$ large, Journal of the London Mathematical Society, 20, 180-189 (1945).

[6] M.L. Cartwright \& J. Littlewood, On nonlinear differential equations of the second order, II: The Equation $\ddot{y}-k f(y) \dot{y}+g(y, k)=p(t)=$ $p_{1}(t)+k p_{2}(t) ; k>0, f(y) \geq 1$, Annals of Mathematics, 48, 472-494 (1947).

[7] M.L. Cartwright \& J. Littlewood, Errata, Annals of Mathematics, 49, 1010 (1948).

[8] M.L. Cartwright \& J. Littlewood, Addendum, Annals of Mathematics, 50, 504-505 (1949).

[9] M.L. Cartwright, Non-Linear Vibrations: A Chapter in Mathematical History. Presidential Address to the Mathematical Association, January 3, 1952, The Mathematical Gazette, 36 316, 81-88 (May, 1952).

[10] W. du Bois Duddell, On Rapid Variations in the Current through the Direct-Current Arc, Journal of the Institution of Electrical Engineers, 30, 148, 232-283 (1900).

[11] W. du Bois Duddell, On Rapid Variations in the Current through the Direct-Current Arc, The Electrician, 46, 269-273 \& 310-313 (1900).

[12] J.M. Ginoux \& L. Petitgirard, Poincaré's forgotten conferences on wireless telegraphy, International Journal of Bifurcation \& Chaos, 20, 11, 3617-3626 (2010).

[13] J.M. Ginoux, Analyse mathématiques des phénomènes oscillatoires non linéaires, Thèse, Université Pierre \& Marie Curie, Paris VI (2011).

[14] J.M. Ginoux, The First "Lost" International Conference on Nonlinear Oscillations (I.C.N.O.), International Journal of Bifurcation 83 Chaos, 4, 22, 3617-3626 (2012) 
[15] J.M. Ginoux \& C. Letellier Van der Pol and the history of relaxation oscillations: Toward the emergence of a concepts, Chaos, 22, 023120 (2012)

[16] J.M. Ginoux, Self-excited oscillations: from Poincar to Andronov, Nieuw Archief voor Wiskunde (New Archive for Mathematics) journal published by the Royal Dutch Mathematical Society (Koninklijk Wiskundig Genootschap), 5, 13, n ${ }^{\circ}$ 3, 170-177 (September 2012).

[17] J.M. Ginoux \& R. Lozi, Blondel et les oscillations auto-entretenues, Archive for History of Exact Sciences, 1-46 (17 May 2012).

[18] J.M. Ginoux, Histoire de la théorie des oscillations non linéaires, Hermann, (Paris), 2015.

[19] J.M. Ginoux, History of nonlinear oscillations theory, Archimede, New Studies in the History and Philosophy of Science and Technology, Springer, (New York), 2016.

[20] J.M.A. Gérard-Lescuyer, Sur un paradoxe électrodynamique, Comptes Rendus de l'Académie des Sciences, 168, 226-227 (16 juillet 1880).

[21] J.M.A. Gérard-Lescuyer, On an electrodynamical paradox, Philosophical Magazine, v, 10, 215-216 (1880).

[22] J. Guckenheimer, K. Hoffman \& W. Weckesser, The Forced van der Pol Equation I: The Slow Flow and Its Bifurcations, SIAM Journal Applied Dynamical Systems, 2, 1, 1-35 (2003)

[23] P. Janet, Sur les oscillations électriques de période moyenne, Journal de Physique Théorique et Appliquée, II, 1, 337-352 (1893).

[24] P. Janet, Sur une analogie électrotechnique des oscillations entretenues, Comptes Rendus de l'Académie des Sciences, 168, 764-766 (14 April 1919).

[25] Ph. Le Corbeiller, Non-linear theory of maintenance of oscillations, Journal of Institution of Electrical Engineers, 79, 361-378 (1936).

[26] A. Liénard, Étude des oscillations entretenues, Revue générale de l'Electricité, 23 901-912 \& 946-954 (1928).

[27] A. Lyapounov, Problème général de la stabilité du mouvement, Annales de la faculté des sciences de Toulouse, Sér. 2 9, 203-474 (1907). 
(Originally published in Russian in 1892. Translated by M. Édouard Davaux, Engineer in the French Navy à Toulon).

[28] Th. du Moncel, Réactions réciproques des machines dynamoélectriques et magnéto-électriques, La Lumière Électrique, II, 17, 352 (1880).

[29] N. Papaleksi, Международная нелинейным конференция, (Internatinal Conference On Nonlinear Process, Paris 28-30 January 1933), Zeitschrift für Technische Physik, 4, 209-213 (1934).

[30] H. Poincaré, La théorie de Maxwell et les oscillations hertziennes : la télégraphie sans fil, Gauthier-Villars, 3e éd., (Paris), 1907.

[31] H. Poincaré, Sur la télégraphie sans fil, La Lumière Électrique, II 4, 259-266, 291-297, 323-327, 355-359 \& 387-393 (1908).

[32] H. Poincaré, Conférences sur la télégraphie sans fil, La Lumière Électrique éd., Paris, 1909.

[33] H. Poincaré, Sur les courbes définies par une équation différentielle, Journal de mathématiques pures et appliquées, (III), 7, 375-422 (1881).

[34] H. Poincaré, Sur les courbes définies par une équation différentielle, Journal de mathématiques pures et appliquées, (III), 8, 251-296 (1882).

[35] H. Poincaré, Notice sur les Travaux Scientifiques de Henri Poincaré, Gauthier-Villars, Paris, 1884.

[36] H. Poincaré, Sur les courbes définies par une équation différentielle, Journal de mathématiques pures et appliquées, (IV), 1, 167-244 (1885).

[37] H. Poincaré, Sur les courbes définies par une équation différentielle, Journal de mathématiques pures et appliquées, (IV), 2, 151-217 (1886).

[38] H. Poincaré, Les Méthodes Nouvelles de la Mécanique Céleste, Vol. I, II \& III, Gauthier-Villars, Paris, 1892, 1893, 1899.

[39] J.B. Pomey, Introduction à la théorie des courants téléphoniques et de la radiotélégraphie, Gauthier-Villars, Paris, 1920. 
[40] B. Van der Pol, A theory of the amplitude of free and forced triode vibrations, Radio Review (London), 1, 701-710 and 754-762 (1920).

[41] B. Van der Pol, Gedwongen trillingen in een systeem met nietlineairen weerstand (Ontvangst met teruggekoppelde triode), Tijdschrift van het Nederlandsch Radiogenootschap, 2, 57-73 (1924).

[42] B. Van der Pol, Over Relaxatietrillingen, Physica, 6, 154-157 (1926).

[43] B. Van der Pol, Over „Relaxatie-trillingen”, Tijdschrift van het Nederlandsch Radiogenootschap, 3, 25-40 (1926).

[44] B. Van der Pol, Über „Relaxationsschwingungen”, Jahrbuch der drahtlosen Telegraphie und Telephonie, 28, 178-184 (1926).

[45] B. Van der Pol, On "relaxation-oscillations", The London, Edinburgh, and Dublin Philosophical Magazine and Journal of Science, (VII), 2 978-992 (1926).

[46] B. van der Pol, Über Relaxationsschwingungen II, Jahrbuch der drahtlosen Telegraphic und Telephonie, 29, 114-118 (1927).

[47] B. van der Pol, Forced oscillations in a circuit with non-linear resistance (reception with reactive triode), The London, Edinburgh, and Dublin Philosophical Magazine and Journal of Science, VII, 3 65-80 (1927).

[48] B. van der Pol \& J. van der Mark Frequency Demultiplication, Nature, 120, 363-364 (1927).

[49] B. Van der Pol, Oscillations sinusoïdales et de relaxation, Onde Électrique, 9 245-256 \& 293-312 (1930).

[50] A. Witz, Des inversions de polarités dans les machines série-dynamos, Comptes Rendus de l'Académie des Sciences, 108, 1243-1246 (juilletdécembre 1889).

[51] A. Witz, Recherches sur les inversions de polarité des série-dynamos, Journal de Physique Théorique et Appliquée, 8E SÉRIE, 1, 581-586 (1889). 